\title{
Ephemeral stream sensor design using state loggers
}

\author{
R. Bhamjee and J. B. Lindsay \\ University of Guelph, Canada \\ Received: 26 July 2010 - Published in Hydrol. Earth Syst. Sci. Discuss.: 31 August 2010 \\ Revised: 7 March 2011 - Accepted: 20 March 2011 - Published: 24 March 2011
}

\begin{abstract}
Ephemeral streamflow events have the potential to transport sediment and pollutants downstream, which, in predominently agricultural basins, is especially problematic. Despite the importance of ephemeral streamflow, the duration and timing of the events are characteristics that are rarely measured. Ephemeral streamflow sensors have been created in the past with varying degrees of success and this paper presents a solution which minimizes previous shortcomings in other designs. The design and setup of the sensor network in two agricultural basins, as well as considerations for data processing are explored in this paper with regard to monitoring ephemeral streamflow at high spatial and temporal resolutions.
\end{abstract}

\section{Introduction}

Streamflow mainly originates from groundwater sources and surface or near-surface runoff draining surrounding hillslopes. Runoff is frequently the greatest cause for concern because it plays the dominant role in flooding and sediment and pollutant transport (Arnell, 2002). It is the degree of hillslope-channel coupling within a drainage basin that often controls the character and quantity of water transported by its rivers. Hillslope-channel coupling is a dynamic phenomenon that is largely controlled by variation in a basins surface saturated area (Dunne and Black, 1970; Quinn et al., 1991; Bardossy and Lehmann, 1998; Burt and Butcher, 1985 ) and the expansion and contraction of ephemeral headwater streams (Day, 1978, 1980; Gregory and Walling, 1968; Morgan, 1972). While our understanding of surface saturated area dynamics is comparably mature, variations in the extent of flowing streams are still poorly understood, leading Bishop et al. (2008) to call for a new international initiative dedicated to the exploration of headwater streams.

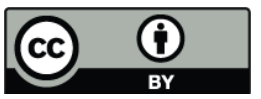

Correspondence to: R. Bhamjee

(rbhamjee@uoguelph.ca)
Ephemeral streams expand and contract with variations in basin moisture conditions (Gregory and Ovenden, 1979). Some ephemeral streams flow during wet seasons and others are episodic, only flowing during and for short periods following heavy rainfall or snow melt. Although ephemeral streams are rarely mapped, they often account for the majority of a catchments total stream length and drain large portions of their basins (Meyer et al., 2007). Therefore, ephemeral streams are important conveyances for water, sediment, nutrients, and pollutants. These wet-weather features provide valuable habitat for aquatic and terrestrial species (Labbe and Fausch, 2000) and affect storm runoff (Poff et al., 1997). Their small channels have comparably high watersediment contact, providing a means for the reduction of phosphorus and nitrogen from runoff (Mulholland et al., 2000; Peterson et al., 2001; Ensign and Doyle, 2006). Additionally, ephemeral streams are important for the cycling of carbon and the retention of sediment within basins (Gomi et al., 2002; Meyer and Wallace, 2001). Ephemeral streams are undoubtedly landscape hotspots and periods of network expansion are hot moments (McClain et al., 2003) of basin process functioning. Unfortunately, our understanding of how stream length varies over a range of spatial and temporal scales is still quite limited (Wigington et al., 2005). This reflects the difficulty in observing the expansion/contraction of flowing streams over long periods at appropriate spatial and temporal resolutions.

\section{Ephemeral stream monitoring}

While there have been relatively few studies involving stream network expansion monitoring, there are various methods that have been tested both in traditional stream monitoring settings and in ephemeral streams that have the potential to be used to understand this phenomenon. Various measurement methods have differing datatypes which they output. The most common outputs for measuring streams are discharge, stage and flow/no-flow.

Published by Copernicus Publications on behalf of the European Geosciences Union. 
The two most important considerations when comparing methods are the spatial and temporal resolution. In regard to measuring stream network extent, spatial resolution refers to the density at which a network of sensors can measure change and is generally limited by cost, but also by practicality (i.e. sometimes there is not enough to be gained by increasing the spatial resolution to outweigh the time and expense of collecting the data). Temporal resolution is the shortest possible event that can be captured by a given measurement technique and is usually limited by the type of data logger used. Two commonly used loggers described in the literature are event and interval loggers.

Event loggers will log a data point whenever the sensor is triggered, such as the tipping of a bucket in a rain gauge. More commonly used is an interval logger, which records a data value at a predetermined amount of time. Interval logging has an inherent trade off between temporal resolution and the length of time the logger can be in the field. To obtain a short logging interval, loggers must have their data downloaded and memory cleared more frequently. In the case of ephemeral streams, which are predominantly dry, the majority of the data will be no-flow values. During notably dry times, the logger may have to be cleared before any flow data is even recorded. Monitoring methods for ephemeral channels range from non-specific methods which have mainly been used in perennial streams, to sensors designed specifically for measuring changes in network extent, each measuring their own aspect of ephemeral stream flow (e.g. discharge, network extent, etc.).

\subsection{Monitoring techniques applicable to ephemeral streams}

\subsubsection{Direct observation}

Day (1978) and Blyth and Rodda (1973) both used direct observation to measure the expansion and contraction of stream networks during storm events. To measure the flowing length of the stream network, Day (1978) set up numbered pegs at $10 \mathrm{~m}$ intervals along a channel and visited the sites during precipitation events, recording how far (i.e. at what numbered peg) the stream network had extended to at a given time during a storm. Measurement was undertaken prior to storms, during the expansion of the network and during the contraction of the network. These attempts were largely hindered by the fact that observers could only take a minimal number of observations at a limited number of sites, making it difficult to gather a fine temporal and spatial representation of the watershed at any given point in time. Day (1978) recorded 16 observations when only small changes in extent were present and only 8 when the network was fully extended. Another issue is the ability of observers to move about the terrain, especially during heavy storms when the streams were at their highest. Direct observation results in a flow/no-flow output at each sampled site and automating the process of monitoring flow has the ability to create finer temporal datasets.

\subsubsection{Current meters}

For perennial and some intermittent streams a current meter can be used to determine velocity and using the velocityarea method, discharge can be determined. Despite the excellent temporal resolution associated with this method, the high cost of the setup means that the ability to monitor over a wide spatial scale is hindered. This method is also not suited to streams with low levels of flow such as many ephemeral streams. To address shallow water and high cost of setup, wading rods can be used to measure flow (Wahl et al., 1995). Wading rods employ a type of portable current meter which are suitable to use in ephemeral streams. These rods however require a person to physically take the measurement, which means that to get a good spatial distribution, many people and instruments must be deployed in a similar manner as the direct observation method used by Day (1978). While this method is similar to direct observation in regard to network extent, the additional output is discharge rather than simply flow/no-flow.

\subsubsection{Pressure transducers}

Pressure transducers are used to measure the depth of water above them by translating the pressure of the water exerted on the sensor (Gupta, 2001) to infer the depth. Using a calibrated cross-section, this flow depth can be converted to discharge. However, the time-consuming nature of this procedure is not well suited to studying stream network and expansion given the need for spatially dense measurements. While this method allows for sensors to be set up along lengths of a stream to determine the network extent the high cost associated with pressure transducers makes it unsuitable for a high spatial resolution. Pressure transducers would require an interval logger which generally results in a lower temporal resolution.

\subsubsection{Optical and acoustic sensors}

Optical and acoustic sensors direct light or sound toward the water surface and measure the time it takes for the pulse to return to the sensor to determine depth. Similar to pressure transducers, using depth data and a calibrated cross-section, it is possible to determine discharge with this method, however, again, the trade-off is the density of the sensor network. While this method is effective in staying clear of debris in the channel it is not well suited to ephemeral channels where debris and sediment may be deposited below the sensor and affect the height it records. Similarly, erosion within the channel during storms would deepen the channel and result in incorrect depths being recorded. This could be corrected with frequent "zeroing" of the sensors in the field. The use of an acoustic or optical sensor for the use of showing flow and no 
Table 1. Lag times for sensor designs.

\begin{tabular}{|c|c|c|}
\hline Sensor & Onset lag & Cessation lag \\
\hline Temperature at $1 \mathrm{~m}^{1}$ & $-19.8 \mathrm{~min}$ & $-108 \mathrm{~min}$ \\
\hline Temperature at $0.05 \mathrm{~m}^{1}$ & $-7.31 \mathrm{~min}$ & $-568 \mathrm{~min}$ \\
\hline Electrical resistance at $0.15 \mathrm{~m}^{1}$ & $3.88 \mathrm{~min}$ & $72.5 \mathrm{~min}$ \\
\hline Electrical resistance at surface ${ }^{1}$ & $-12.1 \mathrm{~min}$ & $70 \mathrm{~min}$ \\
\hline Electrical resistance above surface ${ }^{2}$ & $30 \mathrm{~s}$ & $30 \mathrm{~s}$ \\
\hline Electrical resistance w/state logger & $1 \mathrm{~s}$ & $1 \mathrm{~s}$ \\
\hline
\end{tabular}

1 Blasch et al., 2002

2 Goulsbra et al., 2009

flow events, rather than discharge, is a possibility in channels with minimal erosion and debris as long as the instrument is calibrated often in the field to avoid changes in bed height resulting in false-positives and false-negatives.

\subsubsection{Floats}

Generally, floats are used within stilling wells to measure the stage in the channel (Gupta, 2001). The complexity of setting up stilling wells makes them unsuitable for instances where a high spatial resolution is being sought. Also, stilling wells are not ideal for measuring ephemeral streamflow due to the potential decoupling of ground water and surface water (i.e. some ephemeral streams are likely responding more to surface and near surface runoff inputs rather than ground water). However, the use of a float directly in an ephemeral stream has the potential to measure the stage.

Floats can be used as a measurement device in ephemeral streams to measure the maximum height reached in the channel and whether flow was present during a period of time. By attaching a float to an upright with a toothed configuration that only allows upward movement, the float would move up during times of flow and hold its position unless flow reached a higher level. This method would work in sensing when water was present in a stream and the maximum height reached, however, it would be limited by the need for direct observation and recording of float heights. The relatively low cost of this method would allow a great spatial resolution, however, the physical limitations would minimize its temporal resolution. Using a series of sensors to detect where the float is on the upright could however improve the temporal scale and provide data on water height.

While the preceding methods of observation could be adapted to monitoring stream network extent, attempts have been made to create observation equipment specifically for the measurement of ephemeral streamflow.

\subsection{Specific monitoring techniques for ephemeral streams}

The advent of relatively inexpensive electronics in the 1990s allowed for new, more automated, methods of flow detection to be created. Lower costs meant that a greater spatial resolution could be obtained, while the automation meant that the temporal resolutions attainable were potentially finer than could be achieved through direct observation techniques.

\subsubsection{Temperature sensors}

Temperature sensors buried beneath the channel bed showed a marked difference in temperature when water was present in the stream compared to when the channel was empty (Constantz et al., 2001). The ability to distinguish the presence of water allowed the researchers to infer when there was water in the channel and when it was dry. Using temperature as a surrogate measure for the presence of water in the channel makes this method less robust as it is prone to error from sudden variations in temperature, such as when a cold front passes. The data were difficult to analyze as the temperature signal would ramp up and ramp down, leaving the analyst to decide at what point to consider it streamflow and at what point to consider flow to have ceased (Constantz et al., 2001). Nonetheless, the lower costs of these devices allowed for greater spatial resolution of observations, while automation meant that temporal resolution was finer than direct observation.

\subsubsection{Electric resistance sensors}

An improvement on the temperature based sensor was made by Blasch et al. (2002) when they removed the thermistor from the sensor, thereby creating an electrical resistance (ER) sensor. Instead of measuring fluctuations in temperature, the ER sensor measures changes in electrical conductivity. This method is far more robust than the temperature sensors as the difference in conductivity is significantly higher than the difference in temperature during the presence and absence of water. These shifts in conductivity can be translated into wet and dry events, where high conductivity describes a wet channel and vice versa. While these sensors were tested both above and below the bed surface, Blasch et al. (2002) found that above surface placement provided a more accurate representation of the state of flow. Blasch et al. (2002) tested these sensors in an arid channel using very few sensors, while Goulsbra et al. (2009) were one of the first to collect spatially dense data on ephemeral flows within a single drainage network. Goulsbra et al. (2009) also significantly modified the sensor design first proposed by Blasch et al. (2002) by enclosing the ER circuit within a sensor head designed to shield the device from in-channel debris. Goulsbra et al. (2009) were able to attain a significantly finer spatial resolution than previous efforts by deploying many sensors along the lengths of ephemeral channels in a gullied peatland drainage network located in the Peak District, UK. The sensor design chosen by Goulsbra et al. (2009) was not without its limitations and substantial post-processing was necessary to interpret the beginning and end of flow events. 
Table 2. Comparison of monitoring techniques

\begin{tabular}{|c|c|c|c|c|c|c|}
\hline Sensor & Spatial res. & Temporal res. & Cost & Calibration time & Data processing & Output \\
\hline Current meter ${ }^{1}$ & Very low & Very high & Very high & High & Low & Velocity \\
\hline Wading rod ${ }^{1}$ & Low & Low & High & High & Low & Velocity \\
\hline Observation $^{2}$ & Low & Low & Low-high & Low & High & Flow state \\
\hline Press. transducer ${ }^{3}$ & Low & High & High & High & Low & Stage \\
\hline Optical/audio ${ }^{3}$ & High & High & Low & Low & Med & Stage \\
\hline Floats (stilling well) ${ }^{3}$ & Very low & High & High & Low & Low & Stage \\
\hline Floats (modified) & High & Very Low & Low & Low & Low & Stage \\
\hline Temp. sensor 4 & Very high & Low-high & Low & High & High & Flow state \\
\hline ER sensor ${ }^{5}$ & Very high & Low-high & Low & Low & Low-high & Flow state \\
\hline
\end{tabular}

${ }^{1}$ Based on (Wahl et al., 1995) ${ }^{2}$ (Day, 1978; Morgan, 1972) ${ }^{3}$ (Gupta, 2001) ${ }^{4}$ (Constantz et al., 2001; Blasch et al., 2004) ${ }^{5}$ (Blasch et al., 2002; Adams et al., 2006; Goulsbra et al., 2009)

A summary of the strengths and weaknesses of the preceding monitoring methods can be seen in Table 2 where spatial and temporal resolution are ideally maximized, while cost, calibration time and data processing time are minimized. Using previous monitoring methods, this paper will explore the modification and enhancement of the ER sensor design to better measure changes in stream network extent.

\section{Sensor design}

The sensor was designed to suit the environment typically found in the predominantly agricultural catchments in Southern Ontario. Conditions in Southern Ontario headwater streams include diverse soil types and a range of land covers. Local headwater channels frequently experience high sediment transport and deposition and possess substantial vegetative debris because of the surrounding land-cover which is typically a mixture of agriculture and forest. Another consideration is that with many small animals utilizing the dry channels, there is potential for the sensors to be destroyed by trampling or entanglement with the wires.

The sensor is made up of two distinct parts that were considered independently to meet a set of criteria. The sensor head is the part of the sensor which contains the electrodes and is located in the channel while the logger is a dedicated unit designed to measure and record the responses of the sensor heads.

\subsection{Sensor}

Several environmental factors were considered during the sensor design. Southern Ontario agricultural basins, where the sensors were to be deployed, are made up clayey and sandy soils which are prone to erosion. As such, consideration for how the sensors respond to high sediment transport is important. Along the same lines, many channels have debris which is carried downstream when flow occurs. Thus, the sensor head needed to be designed such that the chances of it being covered in sediment, destroyed by debris in the channels or trampled by local wildlife was minimized. The size of the sensor heads was also an important consideration since the set up and take down of the network would mean transporting them through various terrain types. For this study, a balance between building a small, lightweight sensor and one which could withstand the rigors of the environment needed to be struck. To ensure that these two main criteria were met, various sensor heads were tested in the lab.

A variety of sensor head designs were lab tested in a river tray containing sediment with an average grain size of $0.3 \mu \mathrm{m}$. Flow was initiated from the channel head, flowing downstream. While this is not always how channels initiate, it is representative of the channel when flow is occurring. For each tested sensor head, the slope of the tray was set to 15 , 10 and $\sim 0$ degrees to represent various rates of flow as well as various rates of sediment mobilization. Each sensor head was tested at three locations within the river tray (top, middle and bottom) for a minimum of thirty minutes to ensure that sediment transport results were consistent and comparable between sensor heads. As well, each sensor head tested was oriented in the ideal position, parallel to flow, as well as at a 45 degree angle to the direction of flow. Doing so ensured that the design would not fail in the event that the direction of flow in the channel was not as expected during set up. Each sensor head was also set up in a "clean" state, sitting above the bed as they would be set up in the field, as well as starting them off buried slightly under the bed to simulate the result of a sensor being covered by sediment. Refinements were made on sensor heads that showed promise until a final design was chosen.

For this study, the final sensor head design was created using $2 \mathrm{~mm}$ thick acrylic glass which was curved using a heat gun to the specification in Fig. 1. Acrylic glass was used due to its strength, light weight and the ability to mold it using non-specialized tools. Its plasticity also reduced the chance of a sensor cracking when struck with debris in the channel. The base plate was made of the same thickness acrylic glass 


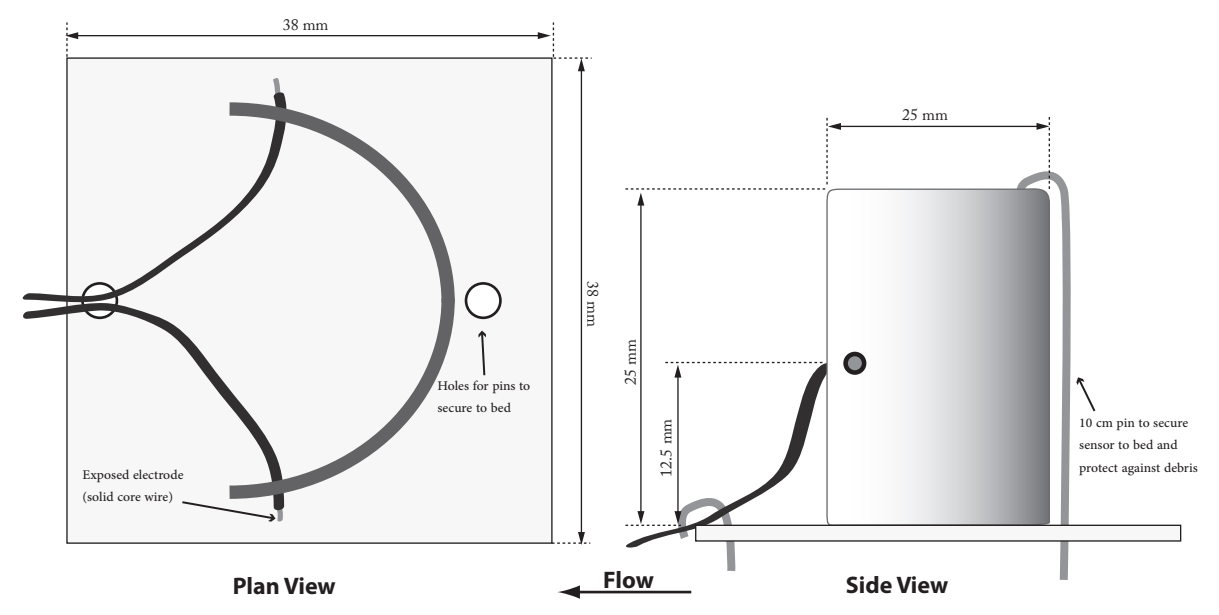

Fig. 1. Electronic resistance (ER) sensor schematic.

cut to $38 \times 38 \mathrm{~mm}$ squares and attached using the same marine glue used to seal the holes in the logger housing. The design was chosen over others due to its simplicity, consisting of only two parts, the cost per sensor $(<\$ 0.50$ per sensor head) as well as its ability to prevent sediment settling on the electrodes. Unlike the design used by Goulsbra et al. (2009), which had the water run through a container using screens to keep out sediment, this design places the electrodes on the outside and avoids the chance of the screens being blocked by sediment. This "open" design means that care needs to be taken to ensure that sediment and other debris do not settle on the electrodes, potentially causing a false-positive (i.e. recording flow when no flow exists). The design mitigates this by placing the electrodes in the areas where erosion around the sensor were shown to occur (Fig. 2). The curved design of the sensor head created an area of higher relative pressure which ensured the sediment did not build up around the electrodes as well as allowing for debris in the channel (e.g. leaves, sticks, etc.) to be deflected away from electrodes rather than being caught up on the front surface. Elevating the electrodes above the baseplate minimized the chance of sediment building up around them as well as ensuring that a signal was not present when water was stagnant (i.e. standing water) on the baseplate prior to it evaporating. By placing the electrodes on either side of the sensor head, the chance of this occurring was further avoided as was the chance that the wires would contact each other (i.e. short circuit). While the sensor head design is an important consideration for detecting flow, the choice in data logger also has an impact on how that flow is recorded and interpreted.

\subsection{Logger}

Since measuring ephemeral stream flow ultimately involves identifying periods of flow and no-flow, there is no advantage to recording the specific electrical conductivity coming from the sensor head such as in the modified temperature logger found in Goulsbra et al. (2009). Rather than recording the electrical resistance of the water, which is not needed to determine flow, state loggers were chosen. State loggers have internal resistance thresholds which are interpreted as being an open or closed circuit, that in the case of ephemeral flow monitoring can be inferred as no-flow and flow states respectively. State loggers record a value only when there is a change in the information coming from the sensor. By contrast, interval loggers will record a value at a predetermined interval, regardless of whether a change has occurred. This monitoring strategy leads to a reduced memory capacity in the loggers when a short interval is used or the trade off of a longer measurement interval (i.e. lower temporal resolution) which is not ideal as stream network expansion is likely to be rapid after intense rainfall events in some catchments. For monitoring ephemeral stream flow timing and duration, event logging is not suitable, as there is concern about both the start and end of flow events. Measurement of ephemeral streamflow timing and duration up to this point have used interval loggers at the expense of temporal resolution.

The use of state logging, as opposed to measuring relative resistance (Goulsbra et al., 2009), eliminates the subjectivity involved in determining the threshold value of electrical resistence seperating open and closed states. Measuring relative resistance, the threshold values are specific to each logger and sensor combination and must be determined through calibration. With state logging, this calibration is not needed as the threshold values are predetermined and constant. Testing was done to ensure that the internal logger resistance cut off were acceptable for measuring flow events. The removal of this calibration process speeds up data interpretation as well as reduces inconsistencies between data loggers. The use of modified temperature sensors in previous studies meant that the data was collected at a predetermined interval to strike a balance between a fine temporal scale and a long data collection period. 


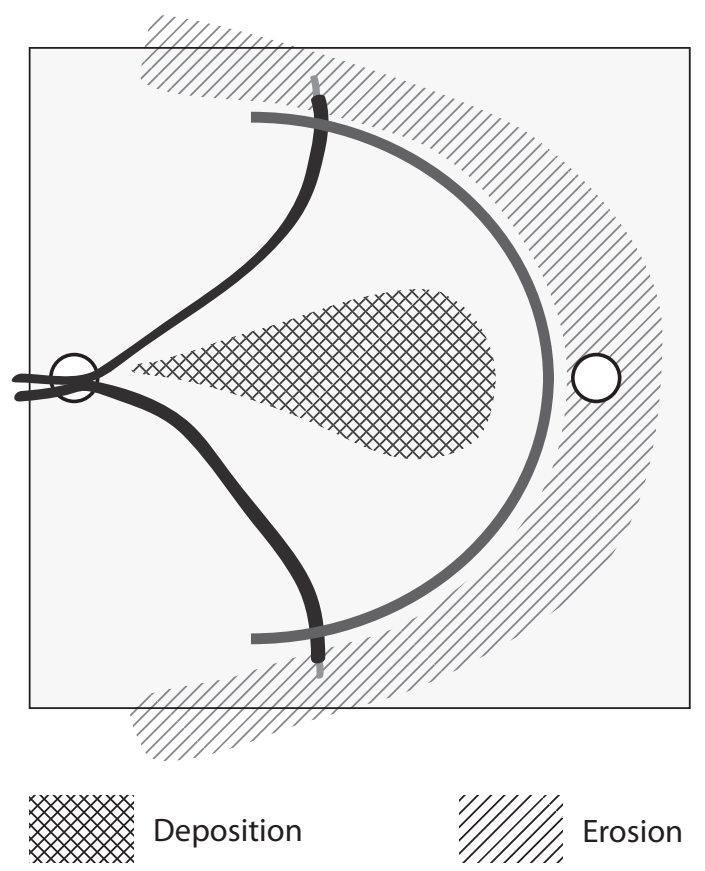

Fig. 2. Schematic of typical erosional and depositional areas around the sensor head under lab conditions.

The chosen data logger for this study was the Onset HOBO U-11 state logger. The U-11 includes three state logging inputs as well as one event input (not used) which allowed for a reduced cost in data loggers compared to previous studies, where each sensor head had a dedicated logger. This reduced per-sensor cost meant that a greater spatial resolution could be achieved at a lower cost. The U-11 logger has a temporal resolution of $1 \mathrm{~s}$, a far higher resolution than the phenomenon being measured, which in combination with the statelogging meant that it had the ability to drastically increase the temporal scale of ephemeral flow data compared to previous designs where logger memory was a limiting factor for temporal resolution.

To test how the U-11 response time compared to previous designs, notably the ER sensors used in Goulsbra et al. (2009), the electrodes were placed into a pan of water to determine the lag times for recording the onset and cessation of flow. Table 3 shows the lag times for the prominent sensor designs used in the literature. Lag times with negative numbers denote where the sensor recorded a false-positive (i.e. the presence of water in the channel, when there was no water present). This is especially an issue with the sensors that were located beneath the surface as they recorded saturated soil as being flow events, thus making them less suited to consistently being able to compare ephemeral streamflow at different sites. With sensors raised above the surface, the lag time is determined by the interval which the logger can record data as well as the time it takes for the water to reach the height of the electrodes. The example in Goulsbra et al.
Table 3. Lag times for sensor designs

\begin{tabular}{|c|c|c|}
\hline Sensor & Onset lag & Cessation lag \\
\hline Temperature at $1 \mathrm{~m}^{1}$ & $-19.8 \min$ & $-108 \mathrm{~min}$ \\
\hline Temperature at $0.05 \mathrm{~m}^{1}$ & $-7.31 \mathrm{~min}$ & $-568 \min$ \\
\hline Electrical resistance at $0.15 \mathrm{~m}^{1}$ & $3.88 \mathrm{~min}$ & $72.5 \mathrm{~min}$ \\
\hline Electrical resistance at surface ${ }^{1}$ & $-12.1 \mathrm{~min}$ & $70 \mathrm{~min}$ \\
\hline Electrical resistance above surface ${ }^{2}$ & $30 \mathrm{~s}$ & $30 \mathrm{~s}$ \\
\hline Electrical resistance $\mathrm{w} /$ state logger & $1 \mathrm{~s}$ & $1 \mathrm{~s}$ \\
\hline
\end{tabular}

${ }^{1}$ Blasch et al., $2002{ }^{2}$ Goulsbra et al., 2009

(2009) used a $30 \mathrm{~s}$ interval as it allowed for the best trade off between temporal resolution and the logger memory available. Since the U-11 loggers check for a change of state every one second, this allows for a very fine temporal resolution, with minimal lag and unlike with an interval logger, the state logger minimizes the trade off.

Since the Hobo U-11 loggers were not designed for outdoor use, logger housings were built using waterproof, sealable storage containers. To accommodate the logger's data input cables, holes were drilled in the side of the housing, allowing just enough room to insert the cables. The use of a marine glue to seal the holes allowed for a reliable waterproof seal and since the glue is able to dry in wet conditions it allowed for the repair of logger housings in the field regardless of the weather, rather than taking a logger offline until it could be redeployed. Finally, both the logger and the sensor were connected to create a field deployable unit.

\subsection{Field-ready sensor}

To create a field ready set of sensors, the sensor heads needed to be attached to the data logger. With three inputs on the U11 data logger, the sensor heads were spaced at $10 \mathrm{~m}$ intervals which provided an adequate spatial resolution. To accomplish this, the outer sensors had two $10 \mathrm{~m} 22$-gauge solid core wires, while the middle sensor had a shorter $30 \mathrm{~cm}$ lead as it would be sitting near the logger when set up. Since two wires ran to each sensor, the pairs were twisted together, which prevented tangling both during transportation and set-up. The ends of the wires on the sensor head side were stripped to expose $2 \mathrm{~mm}$ of wire which minimized the loss of strength and flexibility of the wire when it was exposed, while reducing the chance that fluctuations in temperature would expand the plastic insulation over the end of the wire. The wires were pushed through two holes drilled on either side of the sensor head and were held in place by the same marine glue used to seal the logger housing. In doing so, the wires were held firmly in place and by using marine glue, the chance of having the glue disintegrate when wet was reduced. The sensor heads were held down by two metal pegs, one in front of 


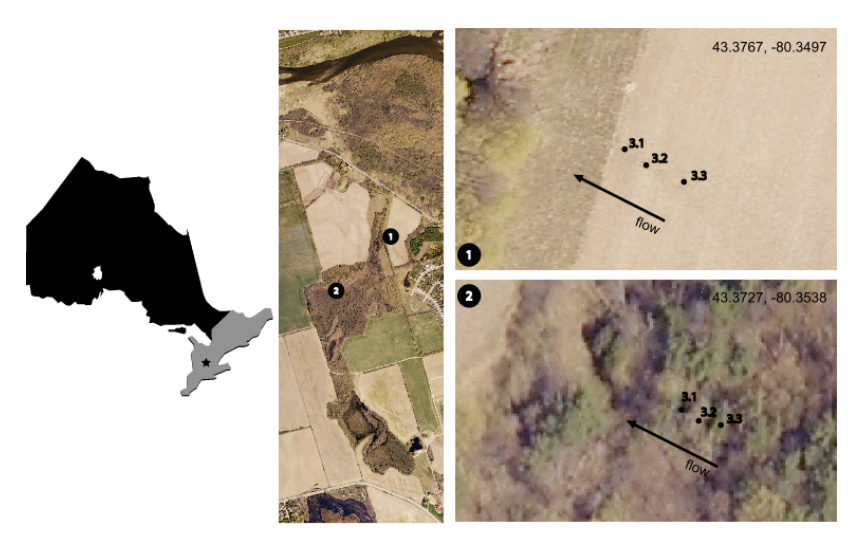

Fig. 3. RARE study sites.

the sensor head and one behind. The placement of the front peg, other than acting as an anchor, also helped to protect the sensor from larger debris

\section{Field set-up and siting considerations}

While extensive lab testing was completed, the sensors needed to be tested in the field to truly determine their usability. Unlike the controlled environment of the lab, the individual constraints on each sensor head were less structured, but tried to account for as many scenarios as the study sites would allow.

\subsection{Study sites}

Field testing occurred at the RARE Charitable Reserve (Fig. 3), which is a part of the Grand River watershed in Ontario, Canada as well as in the Rondeau basin (Fig. 4) in southwestern Ontario .

The RARE Charitable Reserve is mainly composed of active and fallow agricultural fields, forest and low-lying boggy forested areas. The wide variety of land-use/land cover types and sediment types meant the sensors could be tested in many of the characteristic types of landscapes to be found in Southern Ontario. Testing on the site was around Cruickston Creek, which is a tributary of the Grand River. Ephemeral channel widths available on at the site ranged from $10 \mathrm{~cm}$ to over $30 \mathrm{~cm}$ with degrees of slope similar to those used in the lab tests. Available channel depths at the study site ranged from $5 \mathrm{~cm}$ to $15 \mathrm{~cm}$. Vegetation at RARE included mixed deciduous and coniferous forests, fallow fields with tall grasses and plants (e.g. thistle), winter wheat and ground cover type plants in the boggy areas (e.g. skunk cabbage - Symplocarpus foetidus).

The Rondeau basin is located in southwestern Ontario and drains into Lake Erie through a series of deep headwater gullies, which originate on a plateau in the north, and larger streams further downstream in the channel network. Many of the gullies in the area experience emphemeral flow. There are many problems with sediment and nutrient transport within the watershed, especially off of agricultural fields, that have led to severe eutrophication of Rondeau Bay (Lambert, 1997). Frequent in-filling of channels that cross through fields is done to reduce the amount of sediment loss from agricultural fields. Likewise, gullies adjacent to fields tend to be deepened to promote quick removal of water off of tiledrained fields. As a result of steep gullies and anthropogenic modification, the basin has many ephemeral channels in the headlands that run through different types of land-uses/land covers as well as vary in size and depth. The channel widths used for the study ranged from $15 \mathrm{~cm}$ to over $200 \mathrm{~cm}$ while the depths used were between $10 \mathrm{~cm}$ to over $200 \mathrm{~cm}$. Vegetation in the basin is mainly agricultural, with wheat, corn and soybeans being the predominant crop types, however, the catchment also includes deciduous forests and hedgerows separating fields. Unlike the RARE site, the sites in Rondeau did not feed into a single, perennial stream nearby, but rather had a greater spatial distribution and less connectivity via a common stream network.

\subsection{Network installation}

Five sets of loggers, each set containing three sensor heads, were installed within headwater channels of the RARE site to capture each type of land-use in the area. In Rondeau, seven set of loggers, also with three sensor heads were installed within ephemeral channels at the study sites within the basin. Within the channel, sensors were placed in the thalweg to ensure they were in the path of the flow which was not always in the centre of the channel. Each sensor was placed on a local riffle rather than in a pool to minimize the possibility that sensors could be situated in standing water (i.e. puddles within pools) for extended periods. In doing so, the responsiveness of the sensors to actual flow periods was increased. To reduce the likelihood of animals interfering with the wire cables connecting the sensors to the loggers, cables were buried or placed under rocks or logs.

Data loggers were situated near channel banks closest to the middle sensor and were secured in place to prevent movement. The loggers allowed for about 1.5 months of data logging depending on the number of events. Whenever data from the loggers were downloaded, sensors were checked to ensure they were not covered in sediment and if a channel cross-section had changed significantly between field visits, sensors were re-situated within the thalweg.

The sensor design proved to be successful as even in the channels that experienced substantial sediment transport, the electrodes were clear of sediment and debris. Debris in the channel did not affect the sensors despite its presence in many channels. The data loggers and housings were able to withstand the environments they were placed in. 

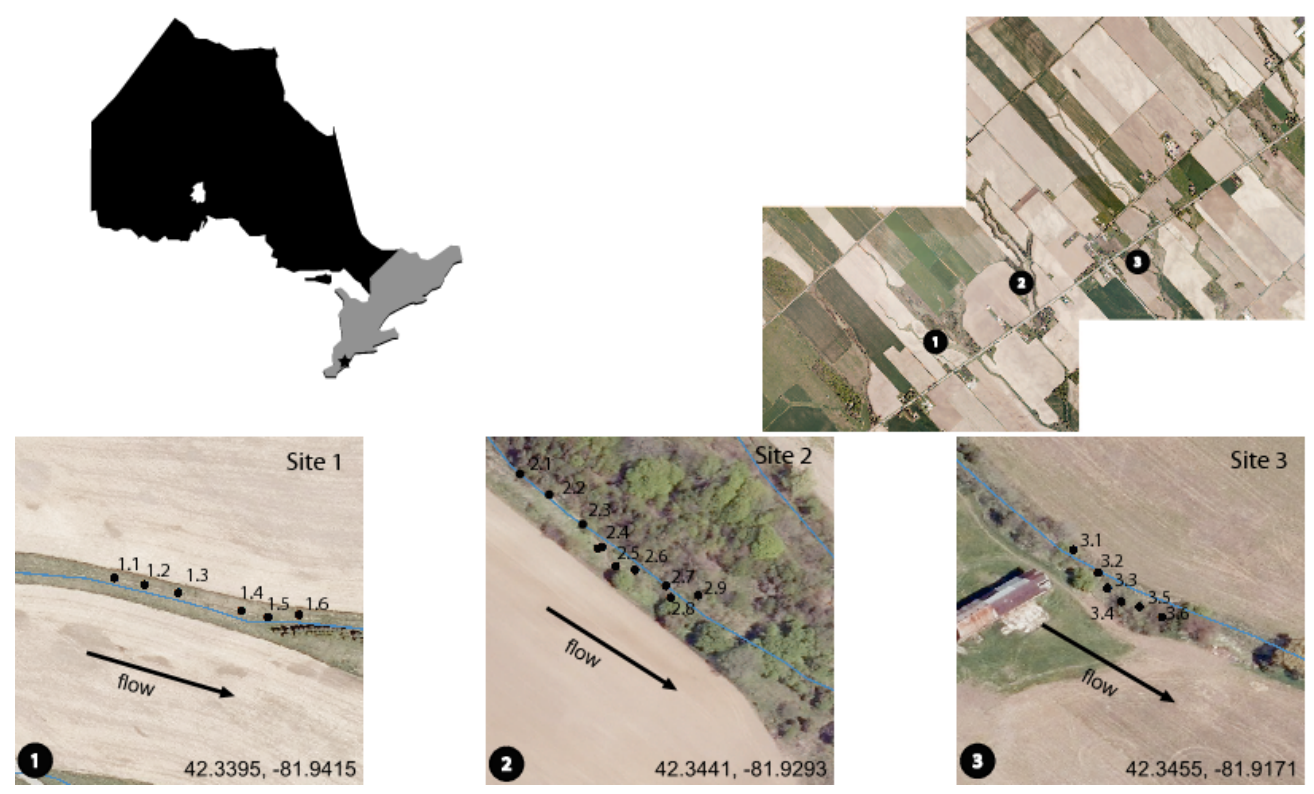

Fig. 4. Rondeau Bay study sites.

\section{Data processing}

Figure 5 shows a sample data set both in raw and postprocessed form. In the raw data set, around the time of a change of state (i.e. from flow to no-flow or vise versa), the state change is associated with numerous and frequent records that can be considered noise. This noise was also observed in lab testing, especially when the channel slope was low. It is believed that this observed noise in the data, around times of changes in state, occurs when the water level is very near the height of the electrodes $(1.5 \mathrm{~cm})$. Ripples in the water surface due to turbulence or wind around the critical level of the electrodes are responsible for these short time-scale changes of state. Figure 6 presents a frequency distribution of the time between state changes in the data set. It is apparent that there is a rapid decrease in the frequency of state changes as events become longer (i.e. actual drying and wetting events).

Noise was removed from the dataset where these changes of state occurred at frequencies greater than $30 \mathrm{~s}$. A $30 \mathrm{~s}$ interval was selected due to fact that it was unlikely that a channel could fill and empty in less than $30 \mathrm{~s}$. To remove noise, the first wet state recorded was selected for the start of a flow event, while the last dry state in the data was selected. It can be assumed that the first wet state is when the water has reached the height of the electrodes, while the subsequent dry and wet data points are the water level fluctuating above and below the electrodes. The last dry state signifies where the water is no longer in flux over the electrodes, meaning that there was either no water in the channel, or very little water which is either stagnant or reducing in depth. Noise events occurred for periods as short as two seconds (two state

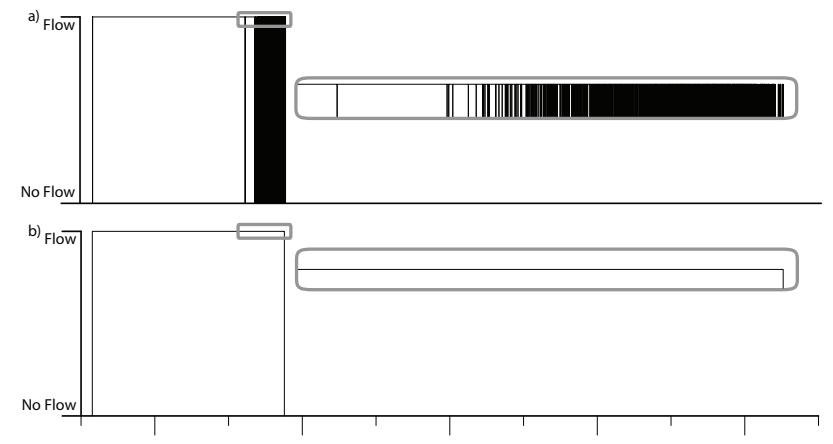

Fig. 5. Raw data (a) and post-processed data (b) with the noise removed for one sensor head.

changes) and as long as about one hour (3600 state changes). The former occured during the onset of flow, while the longer noise events were during cessation periods. This can be compared to a typical hydrograph, where the onset of flow occurs quickly, but the cessation of flow occurs gradually. By removing noise from the data, individual flow events were more easily highlighted and better represented the situation in the channel at the time of the event. The flow state data from Rondeau with the noise removed can be seen in Fig. 7 along with precipitation intensity for the monitoring period.

\section{Network expansion}

When flow is initiated in an ephemeral stream, the stream network expands and likewise, as flow ceases, the stream network contracts. There were three possible modes for stream 


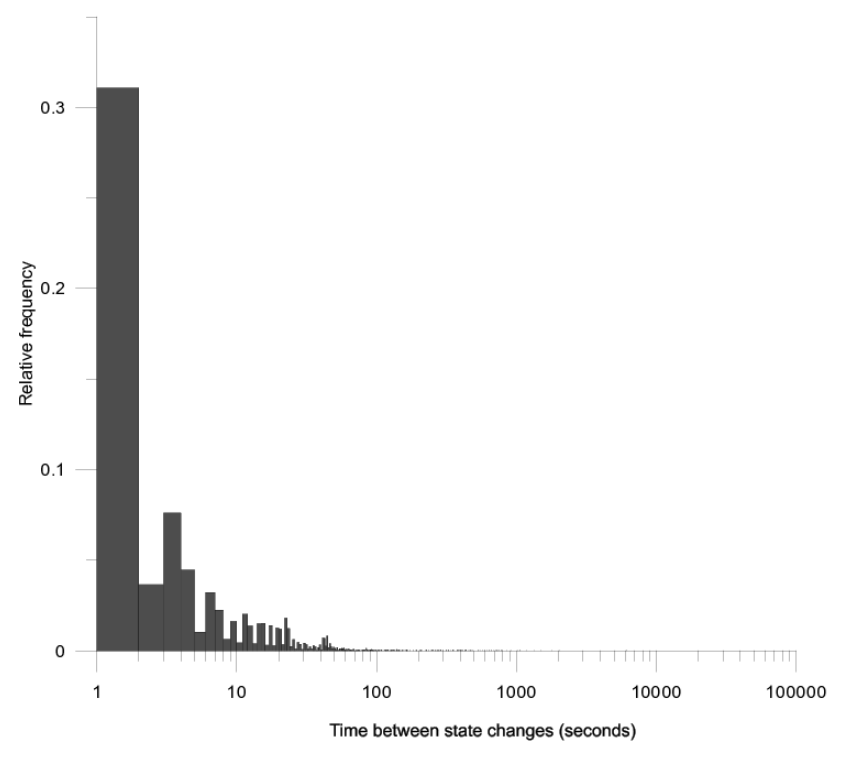

Fig. 6. Histogram showing relative frequency of sensor response times (i.e. off to on and vise versa).

network expansion which were observed in the data (Fig. 8). Headward expansion is the growth of the flowing channel from a downstream position towards the channel head as a result of soil saturation. Downstream expansion is the movement of water from the headland areas which fills the channel from its upper reaches initially and flows downstream until it meets the perennial channel. Downstream expansion is generally caused by the inability for precipitation to infiltrate the surface either due to a high intensity of rainfall and/or low infiltration capacity (Ward and Robinson, 2000). The coalescence model of expansion results when small pools form along the length of the channel until they eventually connect to form a flowing stream. This model of expansion results from the saturation and in-filling of local low spots that eventually expand outward as they fill. There are also instances where a cross-section within a channel may respond, but the stream does not expand. In this case, these single sensor responses can be inferred to be incomplete coalescence.

While three models of expansion exist, there are only two models of contraction: downstream contraction and disintegration (Fig. 9). Downstream contraction occurs as each sensor turns off starting at the channel head, moving downstream (i.e. the stream network dries out from the channel heads down toward the perennial stream). Disintegration, similar to coalescence occurs when flow ceases and local pools remain and drain or lose water through evaporation. Instances where it appears the stream is contracting headward are better described by the disintegration model since continuous flow stops as soon as the bottom-most sensor turns off. Expansion and contraction responses from the study sites can be seen in Tables 4 and 5 as well as the average percent of occurrence for all the sites.
Table 4. Occurrence of each model of expansion as a percent of all events.

\begin{tabular}{|c|c|c|c|c|}
\hline \multicolumn{5}{|c|}{ Stream network expansion } \\
\hline \multirow[b]{2}{*}{ Site } & \multirow{2}{*}{$\begin{array}{r}\text { Downstream } \\
\text { expansion }\end{array}$} & \multirow{2}{*}{$\begin{array}{r}\text { Upward } \\
\text { expansion }\end{array}$} & \multicolumn{2}{|c|}{ Coalescence } \\
\hline & & & Complete & Incomplete \\
\hline 1 & 10 & 15 & 35 & 40 \\
\hline 2 & 5.88 & 5.88 & 23.53 & 64.71 \\
\hline 3 & 0 & 0 & 40 & 60 \\
\hline All sites & 7.14 & 9.52 & 30.95 & 52.38 \\
\hline
\end{tabular}

Table 5. Occurrence of each model of contraction as a percent of all events.

\begin{tabular}{cr|rr}
\hline \multicolumn{3}{c}{ Stream network contraction } \\
\hline Site & $\begin{array}{r}\text { Downstream } \\
\text { contraction }\end{array}$ & \multicolumn{2}{|c}{ Disintegration } \\
Complete & Incomplete \\
\hline 1 & 20 & 40 & 40 \\
2 & 0 & 35.41 & 64.71 \\
3 & 0 & 40 & 60 \\
\hline All sites & 9.52 & 38.09 & 52.38 \\
\hline
\end{tabular}

Incomplete coalescence was the most common occurrence at all three sites, however, these were not showing expansion nor contraction. Coalescence and disintegration were by far the prevalent expansion and contraction models found across all the sites. The related models of coalescence and disintegration accounted for nearly $85 \%$ of all network expansion and contraction events. On a site-to-site basis, expansion and contraction models were found to vary over the course of the monitoring period. As stated earlier, the model of expansion does not always yield the corresponding model of contraction. For instance, site 1 had $10 \%$ of expansion events where downstream expansion occurred and $20 \%$ of events where downstream contraction occurred. Site 3 was by far the least varied site never showing expansion nor contraction by upward expansion or downstream expansion or contraction. Site 2 was also quite consistent with just over $12 \%$ of expansion events being downstream expansion or upward expansion models and all contraction events being disintegration. The way a channel responds is presumably controlled by the characteristics of both the channel itself, as well as processes of water delivery that are ongoing within the adjacent hillslopes.

How an ephemeral stream responds is determined by the manner which water is delivered to the channel from adjacent hillslopes and the way by which the channel delivers the water further downstream. The former is most likely related to catchment characteristics such as soil properties, 

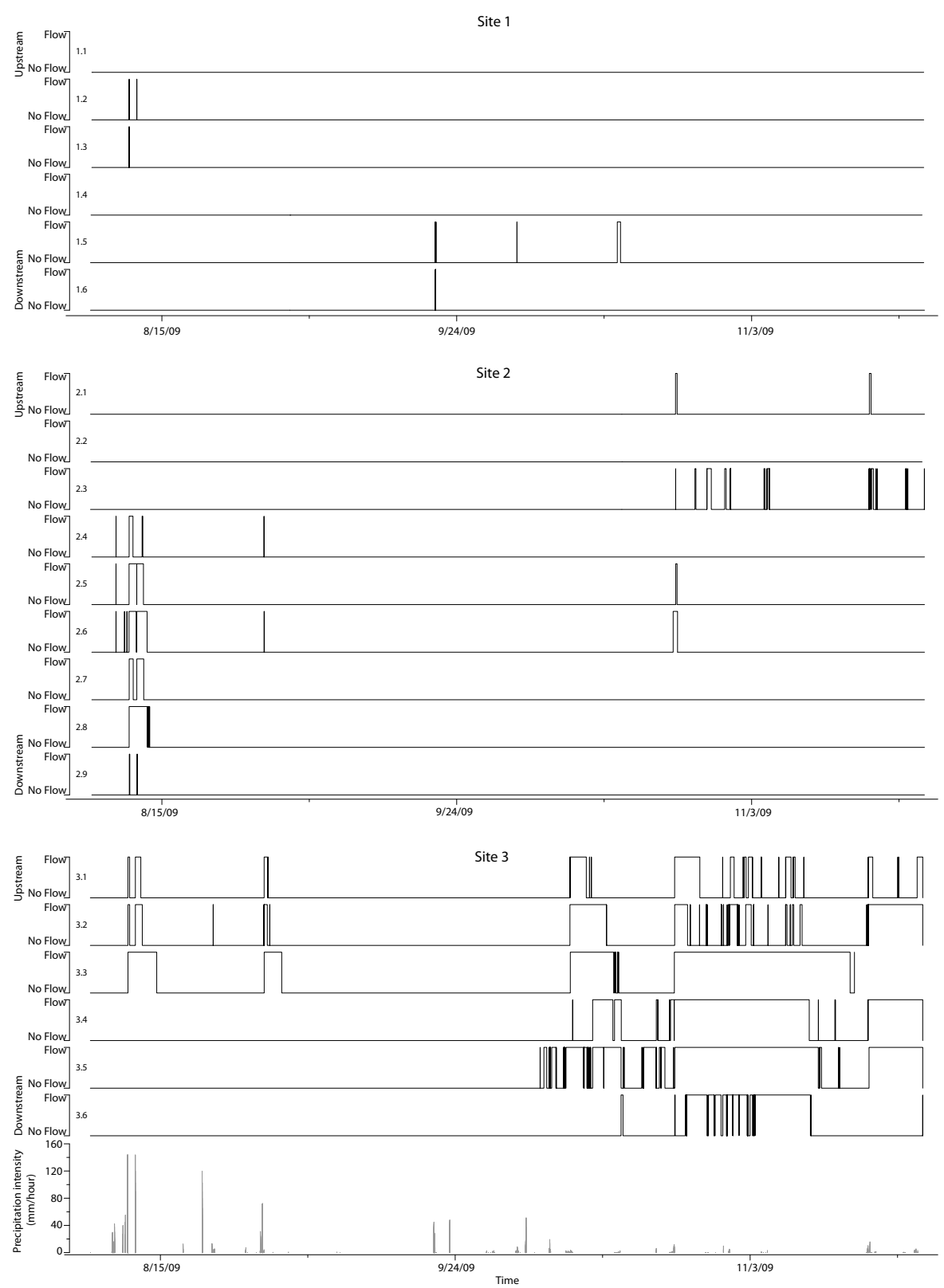

Fig. 7. Final flow data from field with noise removed.

topography, land use/land cover, and anthropogenic activities (e.g. tile drains). In-channel characteristics that are relevant to how the channel delivers water downstream include, cross-sectional channel geometry, longitudinal profile (i.e. slope and pool characteristics), roughness (including the abundance and type of vegetation) and modification of the channel (e.g. straightening, widening, etc.). The combination of these characteristics should affect the manner in which a stream expands and contracts. How a channel expands does not inherently dictate how the channel will contract, nor does the prevalent manner by which the channel expands or contracts guarantee that it will respond the same way under all conditions. However, under similar initial conditions, channels are expected to respond in a similar manner.

\section{Discussion}

Previous ER sensor designs were assessed before designing the sensor in this study. The chosen design has improved the ability to monitor streamflow timing and duration semiautonomously. However, the sensor design was not without its own limitations. 


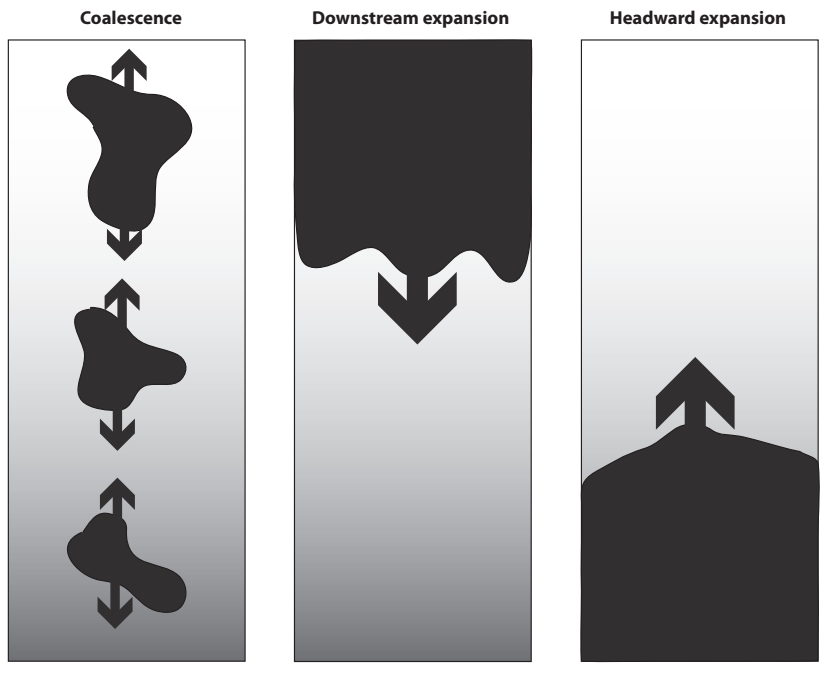

Fig. 8. Models of stream network expansion. Coalescence: the formation of individual pools which join to create a flowing network; Downstream expansion: movement of water from upstream to downstream; Headward expansion: movement of the channel head upstream.

The main limitation of the ER sensor design is that it is only measuring wet and dry states, rather than flow or noflow states. While it can be assumed that in many situations, a wet state will be a flowing state due to the fact that the sensors were places on riffles, it cannot be guaranteed. This has been a limitation of all previous approaches as well, including methods based on ambient bed temperature and ER. Lab experiments have been conducted previously to explore the possibility of measuring flow and no-flow timing directly. These sensor designs were seriously hindered by their lack of robustness in the presence of sediment transport.

While attaching three sensors to a single logger reduced the overall cost of the sensor network, allowing for greater spatial resolution of measurements, logger memory capacity was filled more quickly than it would have if each sensor had a dedicated logger. However, since the logger recorded changes of state, the memory lasted much longer than previous sensor designs where each sensor had its own logger. Another trade-off with having three inputs into one logger was that if a logger failed, three points of measurement along a stream would be lost. While there is no guaranteed way to ensure a logger will not fail for a variety of reasons, frequent monitoring of the sites reduces the chance of this happening. Noise in the data was another factor which needed to be accounted for in the sensor network design and data postprocessing.

While compared to previous attempts, using ER sensors (Goulsbra et al., 2009; Adams et al., 2006), or the bedtemperature method (Blasch et al., 2004) the use of a state logger has allowed for a drastic reduction in post-processing
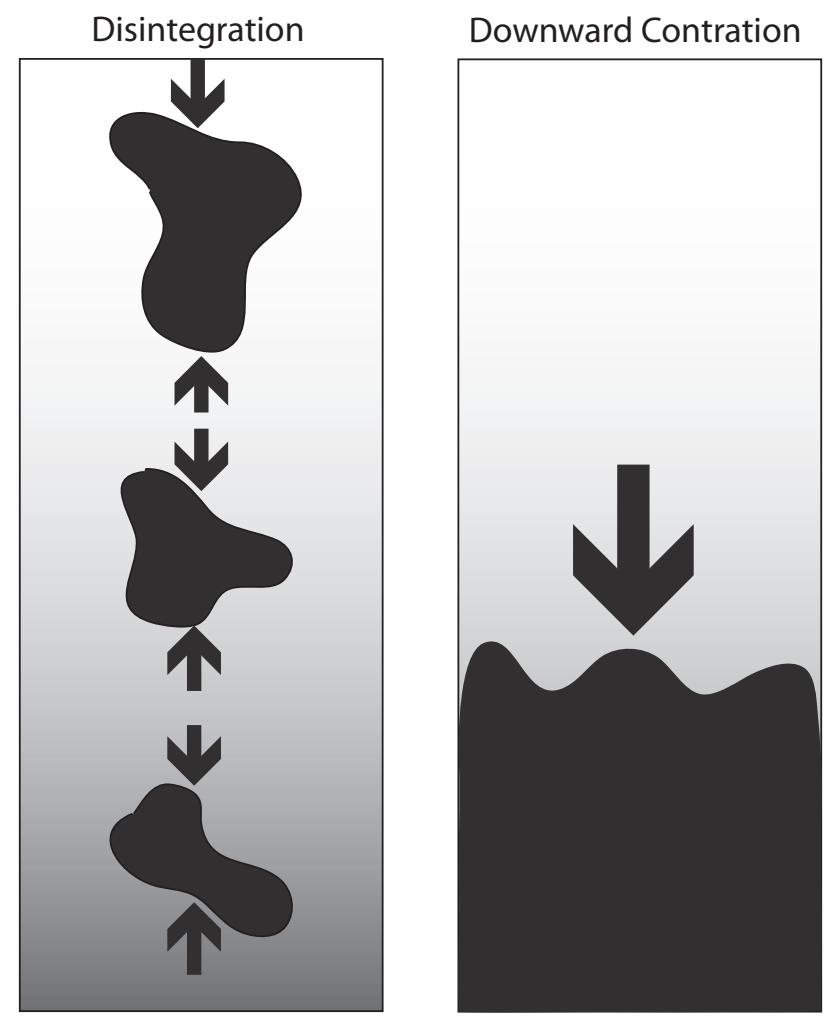

Fig. 9. Models of stream network contraction. Disintegration: the breaking up of a flowing reach into drying pools. Downward contraction: movement of the channel head downstream.

of data while also increasing the temporal resolution because there is no need to determine a sensor-specific threshold in ER. Noise in the data was due to the high temporal resolution of the loggers recording ripples forming on the surface of channel at the level of the electrodes. Site conditions, mainly saturation of soil, affected how quickly streams began to flow. Some channels responded very quickly and showed no noise, while others displayed a slower rise, thus leading to rippling and in turn, noise. While the sensitivity of the current design allows for a very fine temporal resolution which shows the instantaneous rise and fall of the water level above and below the electrodes, a decrease in the sensitivity of the sensor head would allow for cleaner data set for studying longer time frames without the need for post-processing work.

Performance in the lab, under ideal flow patterns, showed significantly less noise in the data compared to the field, except at the lowest channel slopes, and allowed for the controlled testing of various sensor head designs under repeatable, consistent conditions. This would suggest that the noise was caused by small ripples, likely caused by wind, in the surface of the water as it approached the height of the electrodes. While field conditions were far less consistent between channels, the lab testing ensured that the sensors 
worked as expected under the tested flow conditions. The sensors performed well in the field, with the main drawback being that if they were not correctly placed in a channel cross-section, it was possible that low flows were missed as they diverted around the sensor head. Along these same lines, the height of the electrodes meant that any flow in the channel under $12.5 \mathrm{~mm}$ would not have been recorded. However, as coalescence was the dominant model of expansion, measuring these extremely low water levels would not have showed real flow, but rather puddling at an earlier stage. This also has the potential to add significant amounts of noise as described previously. Noise as a result of debris contacting the electrodes was not noticed at any of the sites. The sensor design has allowed for the study of ephemeral streamflow duration and timing in a more quantitative manner.

While the models of expansion presented in this paper are applicable to many landscapes, the scale at which the study is focusing must be considered. At one scale, part of a stream network may appear to expand by way of upward expansion, but when observing the network at another scale, coalescence may be the model which dominates expansion. Accuracy in determining how the entire network expands and contracts hinges on being able to monitor the entire network at fine spatial resolution. Utilizing an inexpensive sensor such as the one presented in this paper will allow for this fine spatial resolution to be determined. Temporal scale is also an important consideration as some channels will flow quickly and having a longer interval will mean that the expansion model could be misrepresented. However, networks will most likely display various models of expansion and contraction depending on the characteristics of each channel and it's surrounding slopes as well as the initial conditions prior to flow.

The ability to deploy the sensors for long periods of time, in a variety of physical environments, has allowed for an improvement in the ability to study the expansion and contraction of stream networks. The cost and ease of setup and maintenance mean that the sensors can be setup at a variety of locations within different regions. This greatly improves the ability to quantitatively compare the behaviour of channels to each other. In doing so, characteristics of each channel can be compared to determine the controls on expansion and contraction as well as observe the manner in which stream networks expand and contract. Knowing this allows for a better understanding of the role headland areas play in the dynamics of the entire watershed. In predominantly agricultural basins, such as Rondeau, this is especially important as the modification and location of these streams has a great affect on downstream water quality and quantity.

\section{Conclusions}

This study describes a novel sensor and monitoring network design for measuring stream flow timing and duration in ephemeral channels in Southern Ontario. The following conclusions can be drawn from this work:

1. State logging lessened the amount of noise in the data and the subjectivity in the interpretation of events when compared to previous attempts at measuring ephemeral streamflow using electrical resistance, while also increasing the responsiveness to flow events and eliminating the need for per-sensor calibration.

2. Spatial and temporal resolution was increased through the use of the state logger. Three inputs allowed for a greater spatial scale due to the lower relative cost and since only changes in state were recorded, temporal resolution was increased relative to previous sensor designs as the logger checked for a change of state every second.

3. Generic models of flow can be used to describe the expansion and contraction of stream networks to study the dynamic of ephemeral steamflow at different scales.

4. Monitoring ephemeral stream duration and timing is needed to understand the dynamics of the flowing stream network. In doing so, the understanding of the migration and fate of pollutants can be enhanced.

\section{Supplementary material related to this article is available online at: http://www.hydrol-earth-syst-sci.net/15/1009/2011/ hess-15-1009-2011-supplement.zip.}

Acknowledgements. Thank you to Stewart Sweeny and Doug Aspinal at OMAFRA and Greg Dunn at MNR for their help with finding study sites in Rondeau and Peter Kelly for his help at RARE.

Edited by: N. Basu

\section{References}

Adams, E. A., Monroe, S. A., Springer, A. E., Blasch, K. W., and Bills, D. J.: Electrical resistance sensors record spring flow timing, grand canyon, arizona, Ground Water, 44(5), 630-641, 2006.

Arnell, N.: Hydrology and global environmental change, Pearson Education, 20002.

Bardossy, A. and Lehmann, W.: Spatial distribution of soil moisture in a small catchment. part 1: geostatistical analysis, J. Hydrol., 206(1-2), 1-15, 1998.

Bishop, K., Buffam, I., Erlandsson, M., Falster, J., Laudon, H., Seibert, J., and Temnerud, J.: Aqua incognita: the unknown headwaters, Hydrol. Process., 22(8), 1239-1242, 2008. 
Blasch, K. W., Ferre, T. P. A., Christensen, A. H., and Hoffmann, J. P.: New field method to determine streamflow timing using electrical resistance sensors, Vadose Zone J, 1(2), 289-299, 2002.

Blasch, K. W., Ferre, T. P. A., and Hoffmann, J. P.: A statistical technique for interpreting streamflow timing using streambed sediment thermographs, Vadose Zone J, 3(3), 936-946, 2004.

Blyth, K. and Rodda, J. C.: A stream length study, Water Resour. Res., 9(5), 1454-1461, 1973.

Burt, T. and Butcher, D.: On the generation of delayed peaks in stream discharge, J. Hydrol., 78(3-4), 361-378, 1985.

Constantz, J., Stonestorm, D., Stewart, A. E., Niswonger, R., and Smith, T. R.: Analysis of streambed temperatures in ephemeral channels to determine streamflow frequency and duration, Water Resour. Res., 37(2), 317-328, 2001.

Day, D. G.: Drainage density changes during rainfall, Earth Surf. Proc., 3(3), 319-326, 1978.

Day, D. G.: Lithologic controls of drainage density: A study of six small rural catchments in New England, N.S.W, CATENA, 7(4), 339-351, 1980.

Dunne, T. and Black, R. D.: Partial area contributions to storm runoff in a small New England watershed, Water Resour. Res., 1970.

Ensign, S. and Doyle, M.: Nutrient spiraling in streams and river networks. J. Geophys. Res., 111(G4), G04009, doi:10.1029/2005JG000114, 2006.

Gomi, T., Sidle, R., and Richardson, J.: Understanding processes and downstream linkages of headwater systems, BioScience, 52(10), 905-916, 2002.

Goulsbra, C., Lindsay, J., and Evans, M.: A new approach to the application of electrical resistance sensors to measuring the onset of ephemeral streamflow in wetland environments. Water Resour. Res., 45(9), W09501, doi:10.1029/2009WR007789, 2009.

Gregory, K. and Ovenden, J.: Drainage network volumes and precipitation in Britain, Transactions of the Institute of British Geographers, 4(1), 1-11, 1979.

Gregory, K. and Walling, D.: The variation of drainage density within a catchment, Bull. Int. Ass. Sci. Hydrol., 13(2), 61-68, 1968.

Gupta, R.: Hydrology and hydraulic systems, Waveland Press, 2001.

Labbe, T. and Fausch, K.: Dynamics of intermittent stream habitat regulate persistence of a threatened fish at multiple scales, Ecological Applications, 10(6), 1774-1791, 2000.
Lambert, L.: Technical report no. 15: degredation of aesthetics, Lake Erie Lakewide Management Plan (LaMP) Technical Report Series, 1997.

McClain, M. E., Boyer, E. W., Dent, C. L., Gergel, S. E., Grimm, N. B., Groffman, P. M., Hart, S. C., Harvey, J. W., Johnston, C. A., Mayorga, E., McDowell, W. H., and Pinay, G.: Biogeochemical hot spots and hot moments at the interface of terrestrial and aquatic ecosystems, Ecosystems, 6(4), 301-312, 2003.

Meyer, J., Strayer, D., Wallace, J., Eggert, S., Helfman, G., and Leonard, N.: The contribution of headwater streams to biodiversity in river networks, J. Am. Water Resour. As., 43(1), 86-103, 2007.

Meyer, J. and Wallace, J.: Lost linkages and lotic ecology: rediscovering small streams. 295-317, Ecology: achievement and challenge. Blackwell Science, Oxford, UK, 406, 2001.

Morgan, R. P. C.: Observations on factors affecting the behaviour of a first-order stream, Transactions of the Institute of British Geographers, 171-185, 1972.

Mulholland, P., Tank, J., Sanzone, D., Wollheim, W., Peterson, B., Webster, J., and Meyer, J.: Nitrogen cycling in a forest stream determined by a $15 \mathrm{~N}$ tracer addition, Ecological Monographs, 70(3), 471-493, 2000.

Peterson, B., Wollheim, W., Mulholland, P., Webster, J., Meyer, J., Tank, J., Marti, E., Bowden, W., Valett, H., Hershey, A., McDowell, W. H., Dodds, W. K., Hamilton, S. K., Gregory, S., Morrall, D. D.: Control of nitrogen export from watersheds by headwater streams. Science, 292(5514), 86-90, doi:10.1126/science.1056874, 2001.

Poff, N., Allan, J., Bain, M., Karr, J., Prestegaard, K., Richter, B., Sparks, R., and Stromberg, J.: The natural flow regime, BioScience, 47(11), 769-784, 1997.

Quinn, P., Beven, K., Chevallier, P., and Planchon, O.: The prediction of hillslope flow paths for distributed hydrological modelling using digital terrain models, Hydrol. Process., 5(1), 59-79, 1991.

Wahl, K. L., Thomas, W. O., and Hirsch, R. M.: Stream-gaging program of the US Geological Survey, 1995.

Ward, R. and Robinson, M.: Principles of hydrology, 450 pp., 2000.

Wigington, P., Moser, T. J., and Lindeman, D. R.: Stream network expansion: a riparian water quality factor, Hydrol. Process., 19(8), 1715-1721, 2005. 